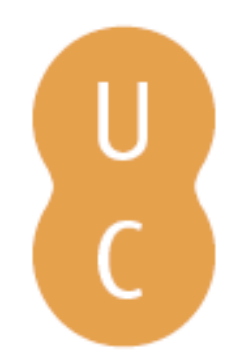

\title{
nombalina
}

\section{“Tal carruaje nos ha dado Helio...": el recurso del carro alado en la Medea de Eurípides}

\author{
Autor(es): $\quad$ Cidre, Elsa Rodríguez \\ Publicado por: Imprensa da Universidade de Coimbra \\ URL \\ persistente: URI:http://hdl.handle.net/10316.2/42944 \\ DOI: $\quad$ DOI:https://doi.org/10.14195/978-989-26-1439-7_1 \\ Accessed : $\quad$ 26-Apr-2023 08:30:59
}

A navegação consulta e descarregamento dos títulos inseridos nas Bibliotecas Digitais UC Digitalis, UC Pombalina e UC Impactum, pressupõem a aceitação plena e sem reservas dos Termos e Condições de Uso destas Bibliotecas Digitais, disponíveis em https://digitalis.uc.pt/pt-pt/termos.

Conforme exposto nos referidos Termos e Condições de Uso, o descarregamento de títulos de acesso restrito requer uma licença válida de autorização devendo o utilizador aceder ao(s) documento(s) a partir de um endereço de IP da instituição detentora da supramencionada licença.

Ao utilizador é apenas permitido o descarregamento para uso pessoal, pelo que o emprego do(s) título(s) descarregado(s) para outro fim, designadamente comercial, carece de autorização do respetivo autor ou editor da obra.

Na medida em que todas as obras da UC Digitalis se encontram protegidas pelo Código do Direito de Autor e Direitos Conexos e demais legislação aplicável, toda a cópia, parcial ou total, deste documento, nos casos em que é legalmente admitida, deverá conter ou fazer-se acompanhar por este aviso.

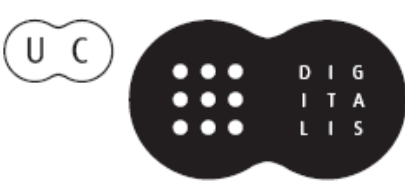




\section{Pervivencia del mundo clásico en la literatura:}

\section{tradición y relecturas}

\section{Aldo Rubén Pricco, Stella Maris Moro (coords.)}

IMPRENSA DA UNIVERSIDADE DE COIMBRA 


\title{
“Tal carruaje nos ha dado Helio...": \\ el recurso del carro alado en la Medea de Eurípides (“Such a car was given us by Helios ...”: the use of a winged car in Euripides' Medea)
}

\author{
Elsa Rodríguez Cidre (elsale@fibertel.com.ar) \\ Universidad de Buenos Aires - CONICET
}

\begin{abstract}
Resumen - Se analiza aquí la simbología del carro de serpientes aladas en el que huye Medea en la tragedia homónima de Eurípides. La escena de cierre corona el proceso de "divinización" de la protagonista a través de la utilización de este singular elemento de la performance teatral griega antigua.
\end{abstract}

Palabras Clave: Eurípides, Medea, carro, theà apò mekhanés, performance.

АвsтRACт - It is analyzed here the symbology of the winged-serpents chariot with which Medea ran away in the homonymous tragedy of Euripides. The closing scene consummates the "deification" process of the protagonist through the use of this unique element of ancient Greek theater performance.

KEywords: Euripides, Medea, chariot, theà apò mekhanés, performance.

Eurípides ha sido considerado siempre un gran innovador del teatro clásico, por ejemplo, al reducir el papel de los coros o al subvertir las pautas habituales de apertura y cierre de las obras. Medea es una buena muestra de ello aun siendo una obra temprana en su carrera (431 a.C.). De hecho, en lo que concierne a su argumento, Eurípides fue el primero en hacer de Medea una filicida, lo que, como sabemos, terminará siendo luego el rasgo de identidad definitorio del personaje mítico ${ }^{1}$. Este dato es fundamental para comprender el modo en que Eurípides desarrolla su trama y para poder calibrar lo que sus primeros espectadores debieron haber experimentado cuando la protagonista se dirigió finalmente hacia la comisión de un doble filicidio. En este sentido, resulta muy significativo el uso de red herrings ${ }^{2}$ que personajes como la nodriza van perfilando en sus discursos, confundiendo al auditorio respecto de qué modalidad cobraría finalmente la venganza de la esposa abandonada. Si apuntamos a las pautas formales, Eurípides también innova en esta tragedia al tratar a Medea como una theà apò mekhanés o dea ex machina ${ }^{3}$. Tal

\footnotetext{
${ }^{1}$ En las versiones previas de la tradición mítica, los hijos de Medea mueren como efecto de sus acciones pero no a manos de ella, sino lapidados por los corintios como castigo por haber portado a la hija de Creonte el vestido y las joyas causantes de su muerte.

${ }^{2}$ Dicha expresión ha sido extraída del ámbito de la crítica cinematográfica y es usada cuando el director/autor da guiños falsos al espectador/lector.

${ }^{3}$ Así se designa un frecuente recurso teatral de la tragedia antigua por medio del cual una divinidad hace su aparición al final de una obra para habilitar una solución al problema
} 
como lo indica la expresión, estas eventuales epifanías son divinas y el hecho de que Medea, una mortal, cumpla ese rol representa una audaz novedad, tanto más si tenemos en cuenta que, además de mortal, Medea es criminal y filicida. En efecto, Eurípides en el devenir de la trama va dando pinceladas de una "divinización" que alcanza su clímax con el lugar que le da a la protagonista en el cierre de la tragedia ${ }^{4}$.

Entre estas innovaciones hallamos el hecho de que Medea huya por el éter en un carro en el que se ha convertido el theologeîn desde el cual profiere sus últimos discursos ${ }^{5}$. Como señala Mastronarde (2002: 38-39), dos son los aparatos mecánicos que estaban en uso en el teatro durante la carrera de Eurípides: la mekbané y el ekkýklema ${ }^{6}$. La demanda de Jasón de ver los cuerpos de sus hijos y su llamado a abrir las puertas habría sugerido a la audiencia que el ekkýklema iba a aparecer pero Eurípides frustra esta expectativa con el inusual uso de la grúa para el escape de Medea con los cadáveres de sus hijos. Podemos detenernos en el juego teatral y escenográfico que se produce con esta innovación. Por un lado, hallamos, en un sentido espacial, un nuevo red herring ya que la mirada era conducida hacia las puertas (el intento de Jasón en 1317 y ss. de forzar una entrada) y el ekkýklema (los cadáveres habrían sido colocados sobre él para revelar por convención lo que estaba dentro de la casa ${ }^{7}$ ) en lugar de hacia la mekhané donde sorpresiva y dramáticamente Medea aparece sobre la casa. Todo esto genera en los espectadores el mismo estado de confusión que está experimentando en el mismo momento el personaje de Jasón. Por otro lado, este recurso de la mekhané determina diferencias de altura en el escenario que hacen a la trama (en cuanto permiten a la protagonista su huida ${ }^{8}$ y que hacen también al proceso de divinización que Eurípides viene ensayando con su personaje. En teoría el estatus cambiado de Medea puede también estar marcado por un cambio en su vestuario en esta escena. Para Sourvinou-Inwood (1997: 290-294), desde su aparición en el verso 214 hasta el 1250 viste un vestido griego normal pero al final (en 1317 y ss.) ella está completamente distanciada del coro, los griegos y la audiencia por la representación de un ornado vestido oriental. Mastronarde (2002: 41-42) considera que sin la guía explícita en el texto que señale el significativo gesto de cambio de vestuario uno debería ser reacio a

planteado en la trama. Tales divinidades aparecían en el theologeîon, plataforma sobre el edificio de la escena o también podían estar sostenidos por una mekhané, suerte de grúa que alzaba al actor hasta el theologeîon o que lo mantenía en el aire durante su intervención.

${ }^{4}$ Cf. Rodríguez Cidre 2012.

${ }^{5}$ Foley 1985: 70-71 analiza el uso de los carros terrestres en el registro trágico: la llegada de Agamenón y Casandra en el Agamenón de Esquilo, la de Clitemnestra en la Electra de Eurípides o la de Ifigenia en Ifigenia en Áulide.

${ }_{6}$ Para un detalle exhaustivo del primero, cf. Mastronarde 1990: 18-20; cf. también Cunningham 1954. Para el segundo, cf. Brioso Sánchez 2006. Cf. también Elliot 1979: 107.

${ }^{7}$ Cf. E. Her. 1030 o A. Ag. 1372.

${ }^{8}$ Mastronarde 2002: 10 detalla los obstáculos con los que se encuentra Medea. 
asumirlo pero sí cree que Medea puede llegar a portar un adorno que marque su nueva condición. De una manera o de otra la filicida refleja escenográficamente su cambio de estatus mientras que Jasón permanece en la skené sin alcanzar nada de lo que pretende.

No solo Medea presenta características divinas sino que su discurso y el recurso al carro dan a entender que los dioses parecen estar de su lado. Las múltiples referencias a la ascendencia de la protagonista en el dios sol Helio y las también numerosas invocaciones a esta divinidad señalan la injerencia del dios en el destino de su descendiente en función del lazo parental pero también del papel que el sol tiene como testigo de los juramentos violados. Por una razón u otra, Helio entrega el carro salvador a su nieta sin mediar un pedido expreso a este tipo de ayuda?

¿Qué características tiene este carro? Si nos atenemos al texto la propia

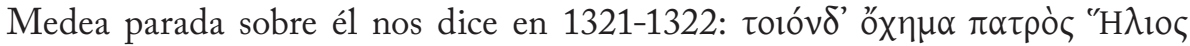

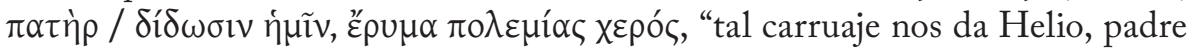
de mi padre, amparo de la mano enemiga" ${ }^{10}$. El término usado, óx $\mu \alpha$, remite en general al carro tirado por mulas y se halla opuesto a öp $\mu \alpha$ en tanto carro de guerra ${ }^{11}$. No hay mayores precisiones salvo en lo que concierne a la protección de la divinidad que aquí es explícita y crucial. Si uno retrocede unos versos,

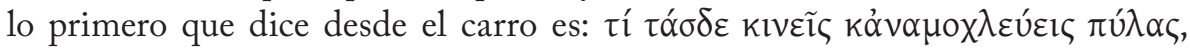

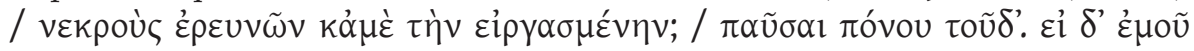

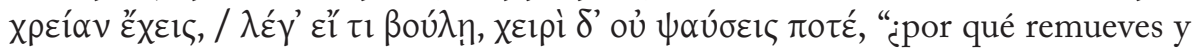
violentas estas puertas buscando los cadáveres y a mí, la perpetradora? Cesa en ese esfuerzo y, si tienes necesidad de mí, di si quieres algo, pero no me tocarás nunca con tu mano" (1317-1320). Esta es la primera línea hablada por Medea en su sorprendente y espectacular aparición en el carro enfatizando el amparo que este representa y con el cual huirá volando.

Ahora bien, la tradición afirma que este carro es conducido por serpientes o dragones alados y, como veremos, así se lo suele representar en el registro iconográfico. ¿Qué otros datos tenemos del don de Helio? El mensajero en 1122-

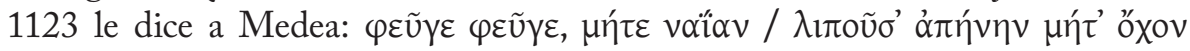
$\pi \varepsilon \delta \circ \sigma \tau \imath \beta \tilde{\eta}$, "huye, huye, no renuncies ni a un transporte marino ni a un carro de tierra" ${ }^{12}$. Si bien no hay otra referencia explícita al carro uno no puede dejar de pensar en las palabras de Jasón de los versos 1296-1298 cuando buscando a la

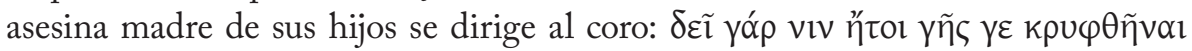

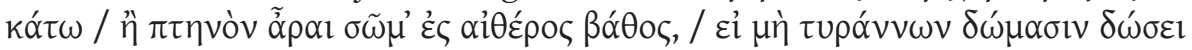

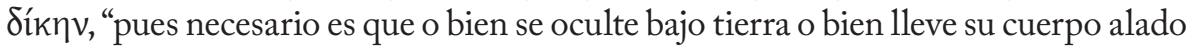

\footnotetext{
${ }^{9}$ Cf. Mastronarde 2002: 32.

${ }^{10}$ La edición base es la de Diggle y la traducción nos pertenece.

${ }^{11}$ En el registro trágico aparece en: S. El. 740, E. Alc. 67, Supp. 662, Rh. 621.

${ }^{12}$ Cf. Page 1955: 153; Elliot 1979: 95.
} 
hacia el profundo éter, si no quiere pagar el crimen al palacio de los reyes". El vuelo alado que Jasón ve como imposible, pronto aparecerá desde lo alto mostrando el poder de Medea ${ }^{13}$. No hallamos aquí referencias a los dragones y, por otra parte, el carro sobre el cual el Sol se mueve portando la luz del día de Oriente a Occidente comúnmente es representado tirado por bueyes o caballos. Pero el detalle de que esté tirado por sierpes aparece en la primera hipótesis de la tragedia (esta vez con el vocablo que remite a carro de guerra, $\alpha$ $\rho \mu \alpha)$ : “...y Medea, después de matar a sus propios hijos, en el carro de serpientes aladas ( que recibió de Helio, sale transportada para Atenas y en aquel lugar se casa con Egeo, hijo de Pandión". La tradición también se asienta en el texto del escolio al verso 1320 donde se dice que el vehículo es tirado por dragones alados ${ }^{14}$.

En este punto, nos hallamos en un terreno de conjeturas. El texto solo dice que se trata del carro de Helio y se entiende que vuela. Sin embargo, la datación de las representaciones iconográficas de la huida de Medea permite suponer que la innovación euripidea incluía también a los dragones alados ${ }^{15}$. En efecto, después del 431 a. C., fecha de la puesta de $M e d e a^{16}$, la protagonista aparece representada como filicida $y$, a veces, como maga oriental mientras que con anterioridad el tratamiento iconográfico era más diversificado (el episodio de las hijas de Pelias y la imagen del caldero, por ejemplo, era más frecuentado ${ }^{17}$. En cuanto a Medea y el carro, no hay rastro de producción artística ática. Todas las imágenes provienen del área itálica, en particular de la cerámica italiota y, en época romana, de los sarcófagos y de los frescos de la pintura parietal. Veamos, pues, los vasos que han relevado los historiadores del arte en lo que hace a la huida de Medea y el carro de Helio ${ }^{18}$ :

(I) hidria de Policoro (Museo Nazionale della Siritide, c. 400 a.C. -35296): Medea con vestimenta extranjera y gorro frigio en un carro tirado por sierpes

${ }^{13}$ Cf. Mastronarde 2002: 374. Page 1955: 175 señala que el 1327 de Jasón (ク̋入ı́o $\tau \varepsilon$

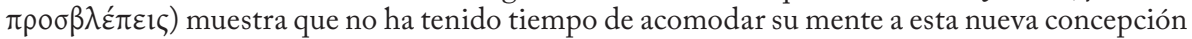
del Sol. Su horrorizada exclamación es la convencional expresión de la idea griega de que el Sol está contaminado por la mirada de los que están en falta.

${ }^{14}$ Cf. Elice 2004: 17.

15 Elice 2004: 31 señala que lo maravilloso en el mito de Medea está estrictamente relacionado con el elemento mágico ya que el motivo del dragón unifica los dos extremos del evento mítico: la Medea princesa de la Cólquide y la Medea mujer engañada en busca de venganza en Corinto, la joven maga capaz de cerrar el curso de los astros, de invocar al Sueño y de encantar al dragón custodio del vellocino de oro y la madre filicida que huye salvada en el mágico carro del Sol, tirado por dragones alados.

${ }^{16}$ Recordemos que participó por primera vez en el 455 a. C. con una tetralogía en la que figuraba Las Pelíadas, primera tragedia del poeta sobre el personaje de Medea y que trataba acerca de la venganza que ella ejerce al convencer a las hijas de Pelias de descuartizarlo y hervirlo en un caldero.

${ }^{17}$ Cf. Elice 2004: 22.

${ }^{18}$ Cf. Galasso 2013, Elice 2004: 22-23, Mastronarde 2002: 66-69, Guiraud 1996. 
“Tal carruaje nos ha dado Helio...”: el recurso del carro alado en la Medea de Eurípides

y debajo los cuerpos de sus hijos, llorados por una figura arrodillada (que puede ser el pedagogo) y Jasón con una espada desenvainada;

(II) crátera de Cleveland (Cleveland Museum of Art, c. 400 a.C. -1991.1): imagen similar a la anterior pero dentro de un nimbo de rayos solares con un daimon a cada lado; debajo los cuerpos de sus hijos sobre un altar, llorados por una anciana y un hombre (la nodriza y el pedagogo) y Jasón mirando;

(III) ánfora de Nápoles (Museo Archeologico Nazionale, 340-330 a.C. -81954): Medea con vestimenta griega en un carro tirado por serpientes con el cuerpo de un hijo sobre el piso del carro, el otro sobre el suelo debajo; un daimon que sostiene fuego en frente del carro entre este y Selene;

(IV) crátera de San Petersburgo (Hermitage, 340-330 a.C. -Б 2083): Medea con vestimenta griega en un carro tirado por serpientes sosteniendo el cuerpo de cada hijo en cada brazo;

(V) crátera de Munich (Staatliche Antikensammlung, c. 330 a.C. -3296): en la banda superior Creonte agarrando a su hija muerta sobre el trono y otros personajes llorando o corriendo por ayuda; en la banda inferior Medea con vestimenta extranjera a punto de apuñalar a un hijo mientras un carro tirado por serpientes conducido por un daimon la aguarda; hacia la izquierda un joven armado protege los ojos del otro hijo y hacia la derecha el fantasma de Eetes mira.

De I a III, si bien hallamos tanto el filicidio como el carro no asociados con Medea previo a Eurípides, las correspondencias con el texto de la tragedia no son completas (el cuerpo o los cuerpos de los hijos permanecen fuera del carro; aparecen estas figuras llorosas, etc.). Cabe notar que las serpientes en este primer conjunto no aparecen dotadas de alas. En contraste, se puede ver la imagen IV como una ilustración del final de Eurípides o, por lo menos, como una representación más fiel y aquí las sierpes sí son aladas. Por último, la $\mathrm{V}$ muestra un interés casi teatral en los momentos de violencia que en la obra son narrados pero nunca vistos en escena.

Este relevamiento ha suscitado en la crítica múltiples hipótesis. Por una parte, es dable suponer que la obra euripidea se puso en escena con dragones alados y que esto se trasladó al registro iconográfico tal como ocurrió con el motivo del filicidio. Pero también surgen dudas al respecto ya que la evidencia iconográfica presenta discordancias con el relato euripideo, las cuales pueden interpretarse como consecuencia de la inspiración de alguna otra obra literaria, de una puesta en escena posterior en el mundo de la Magna Grecia, o incluso como una innovación propia del registro iconográfico no dependiente del ámbito teatral. Por ejemplo, podría tratarse de la transposición a Medea de una imagen frecuente, la del carro de Triptólemo, héroe representado con un vehículo de sierpes aladas en los vasos áticos desde c. 480 y $470^{19}$. Desde este último punto de vista, se podría invertir el razonamiento y suponer que los autores de la hipótesis

\footnotetext{
${ }^{19}$ Descripto por la temprana obra epónima de Sófocles (fr. 596). Cf. Mastronarde 2002: 377.
} 
o el escoliasta trasmiten al texto euripideo una recreación mítica que el tragediógrafo no tiene por qué haber tenido en mente.

Ahora bien, lo cierto es que la imagen de los dragones alados, original o no de Eurípides, es muy funcional para el diseño del personaje de Medea y además resulta compatible con el estilo de construcción de la trama euripidea. La imagen de una serpiente alada condensa elementos ctónicos y uranios ${ }^{20}$ que encajan perfectamente con la doble identidad de Medea en tanto ser mortal e inmortal, y también como un ser con claras referencias ctónicas (en particular su asociación con la diosa Hécate) pero también uranias (su ascendencia divina ligada al Sol). Un eco de esta duplicidad paradójica (la hibridez de estas serpientes las reenvía al mundo de lo monstruoso) podemos encontrar en el discurso de Jasón cuando hipotetiza como un adýnaton la posibilidad de que la asesina, para evadirse de su venganza, deba ocultarse bajo tierra o elevarse en vuelo hacia el éter (12961298). Este tipo de ironías con discursos previos de otros personajes es típico del estilo euripideo.

Por otra parte, en el registro iconográfico las serpientes presentan una fuerte relación con Medea (que Séneca llevará a su punto máximo). Mastronarde (2002: 377-378) señala que estos animales son asociados desde muy tempranamente con Medea como una figura (o diosa) con poderes mágicos: una representación etrusca del s. VII aparece para mostrar su confrontación en una sierpe de tres cabezas con otra detrás de ella ( $L I M C$ s.v. Medeia, $\left.\mathrm{n}^{\circ} 2\right)$; y una serie de cuatro vasos áticos de figuras negras del período 530-500 muestran el busto de una mujer flanqueado por estos reptiles y uno de los cuatro etiqueta a la mujer, Medea ( $L I M C$ s.v. Medeia, $\mathrm{n}^{\circ}$ 3-6). El autor concluye que dichas imágenes no prueban que el carro de serpientes ya estuviera asociado a Medea pero indica por qué habría sido apropiado para ella. Así es posible que la utilería usada en el 431 a. C. fuera ya un carro de sierpes aunque no se pueden descartar las otras hipótesis.

Todas estas observaciones nos permiten concluir que en esta tragedia de Eurípides el motivo de la huida en un carro que vuela (con o sin serpientes aladas) reviste una importancia fundamental en el diseño del personaje y en la construcción del relato, ambos coronados en la apoteosis triunfante de una Medea que se ha vengado de todos sus enemigos y que no solo sale indemne sino que parte hacia un futuro mejor. Pero si es cierto que después de Eurípides no hay Medea que no sea filicida, sí encontramos Medeas que no huyen en carro alguno. Innumerables recreaciones del mito de la madre asesina terminan con el filicidio (como en la ópera de Cherubini o el film de Pasolini) sin necesidad de dar cuenta del futuro de la mujer bárbara. En ocasiones, la huida puede adoptar cierta forma banal como en el taxi amarillo al que se sube la protagonista de $A s i$ es la vida de Arturo Ripstein del año 2000, quien al son de un bolero deja atrás

\footnotetext{
${ }^{20}$ Cf. Elice 2004: 17.
} 
los cadáveres de sus hijos en manos de un padre estupefacto mientras se encamina hacia la salida de la vecindad para tomar un taxi que terminará encuadrado en la imagen, recurrente en esta película, de una pantalla de televisión.

Entonces la huida de Medea es central en Eurípides mas puede no ser relevante para las recreaciones posteriores. Pero cabe preguntarse, respecto de aquellos que sí deciden poner en escena el motivo del carro de Helio, qué estrategias de performance llevan adelante para resolver esta mezcla de utilería y escenografía que configuraba el theologeîon/carro de la obra euripidea.

Para ilustrar estas posibles soluciones vamos a centrarnos en tres representaciones modernas que apelan a mecanismos bien distintos. En primer lugar, tenemos la Medea del japonés Yukio Ninagawa de 1978/1983. E1 decorado y los vestuarios así como el estilo oriental de la actuación generan un contundente efecto de exotismo para el espectador occidental. Y sin embargo, en lo que respecta al motivo del carro de Helio, la puesta de Ninagawa aparece como una versión fidelísima ya que en un gigantesco despliegue técnico y de abordaje escenográfico el carro desde el cual Medea enseña a Jasón los cadáveres de sus hijos literalmente vuela por el aire hasta perderse de vista. Cabe notar que el carro aparece adornado con grandes alas que, convencionalmente, podrían pensarse de dragón.

Una elección bien distinta es la que se ensaya en la representación de Medea en el Teatro Griego de Siracusa de 2009 en la que se privilegió la diferencia de altura entre Jasón y Medea así como la referencia al dios Helio. En efecto, el carro aparece como una gran bola de fuego desde la que suena la voz y se dibuja la silueta de la bárbara vengadora cuyo vestuario y vehículo vienen a confundirse. E1 descenso de esta esfera solar, su "apagarse", da lugar al fin de la obra misma.

Por último, una versión local, la puesta dirigida por Pompeyo Audivert en el Teatro San Martin de la ciudad de Buenos Aires en 2010/2011. Allí no encontramos utilería ni maquinaria escénica sino que en los segundos finales Medea, en una brillante economía de recursos, toma los brazos de los niños asesinados como si fueran las riendas del vehículo y el zarandeo de estos cuerpos genera no solo el efecto imaginario de estar conduciendo un carro que se confunde con la carne de los hijos muertos sino también un efecto de distancia cada vez mayor con el resto de los actores que están sobre el escenario pocos pasos atrás y en el mismo nivel de altura. El lenguaje corporal aquí suple la utilización de un implemento técnico que denote el carro pero ello ocurre sin negarle presencia real en escena e incluso lo llena de una carga semántica a la vez ajena y fiel al texto euripideo. 
Elsa Rodríguez Cidre

\section{Bibliografía}

\section{Fuentes}

Diggle, J. (1984), Euripidis Fabulae I. Oxford: University Press.

Elliot, A. (1979 [1969]), Euripides. Medea. Oxford: University Press.

Mastronarde, D. J. (2002), Euripides. Medea. Cambridge: University Press.

Page, D. L. (1955 [1938]), Euripides. Medea. Oxford: Clarendon Press.

\section{Estudios}

Brioso Sánchez, M. (2006), "Sobre la maquinaria teatral en la Atenas clásica: el ekkyklema”, Habis 37: 67-85.

Cunningham M. P. (1954), "Medea apo mechanes”, CPh 99: 151-160.

Elice, M. (2004), “I draghi alati di Medea”, in Bianchi, O., Thévenaz, O. (eds.), Mirabilia. Conceptions et représentations de l'extraordinaire dans le monde antique, Actes du colloque international (Lausanne, 20-22 mars 2003). Bern, Peter Lang: 15-34.

Foley, H. (1985), Ritual Irony. Poetry and Sacrifice in Euripides. Ithaca \& London: Cornell University Press.

Galasso, S. (2013), "Pittura vascolare, mito e teatro: l'immagine di Medea tra VII e IV secolo a. C. Saggio e galleria”, Engramma 107,

http://www.engramma.it/eOS2/index.php?id_articolo=1378

Guiraud, H. (1996), “La figure de Médée sur les vases grecs”, in Menu, M. (ed.), Médée et la violence (Pallas 45). Toulouse, Presses Universitaires du Mirail: 207-218.

Mastronarde, D. J. (1990), "Actors on High: The Skene Roof, the Crane, and the Gods in Attic Drama”, Classical Antiquity 9: 247-294.

Rodríguez Cidre E. (2012), "Divinizar lo deshumanizado: la apoteosis en Medea de Eurípides”, in Atienza, A. et alii (eds.), Nóstoi. Estudios a la memoria de Elena Huber. Buenos Aires, Eudeba: 361-370.

Sourvinou-Inwood, C. (1997), "Medea at a Shifting Distance: Images and Euripidean Tragedy", in Clauss, J. \& Iles Johnston, S. (eds.), Medea. Essays on Medea in myth, literature, philosophy and art. Princeton, University Press: 254-296. 